\title{
Influence of Furfuryl Alcohol Fiber Pre-Treatment on the Moisture Absorption and Mechanical Properties of Flax Fiber Composites
}

\author{
Yunlong Jia * (1) and Bodo Fiedler (1) \\ Institute of Polymer and Composites, Hamburg University of Technology (TUHH), Denickestrasse 15, \\ D-21073 Hamburg, Germany; fiedler@tuhh.de \\ * Correspondence: yunlong.jia@tuhh.de; Tel.: +49-40-42878-2536
}

Received: 31 July 2018; Accepted: 17 August 2018; Published: 19 August 2018

\begin{abstract}
Poor moisture resistance of natural fiber reinforced bio-composites is a major concern in structural applications. Many efforts have been devoted to alleviate degradation of bio-composites caused by moisture absorption. Among them, fiber pre-treatment has been proven to be effective. This paper proposes an alternative "green" fiber pretreatment with furfuryl alcohol. Pre-treatments with different parameters were performed and the influence on the mechanical properties of fiber bundles and composites was investigated. Moisture resistance of composites was evaluated by water absorption tests. Mechanical properties of composites with different water contents were analyzed in tensile tests. The results show that furfuryl alcohol pretreatment is a promising method to improve moisture resistance and mechanical properties (e.g., Young's modulus increases up to $18 \%$ ) of flax fiber composites.
\end{abstract}

Keywords: durability; green composites; cellulosic fibers; water uptake

\section{Introduction}

Sustainable development has increasing importance nowadays. Many efforts have been devoted to reducing greenhouse gases emission and avoiding mass production of products from non-renewable resources. In the field of advanced composite materials, bio-composites (we only refer to plant fibers and bio-based polymers in this work) and their applications gain increasing interest in many industries [1-3]. Apart from the self-evident advantage of reduced environmental impact, bio-composites exhibit acceptable specific mechanical properties [4,5]. Plant fibers have other advantages of low cost, low density, easy handling, non-abrasive nature, etc. [6,7]. Their applications in composites can now be found in automotive, sports, transport vehicles and construction industries [8-10].

Despite the promising mechanical properties of bio-composites that have been proven by many researchers, applications of bio-composites in structural components are still hindered by several challenges $[6,11]$. Major concerns lie in the hydrophilia of plant fibers, which brings two problems: the poor compatibility between hydrophilic plant fibers and hydrophobic polymer matrix and the low moisture resistance of bio-composites, which is related to durability of bio-composites. Indeed, plant fibers, as cellulosic fibers, are abundant in polar functional groups such as hydroxyl groups. When bio-composites are exposed to humid atmosphere or rain, absorbed water molecules in the composites are very susceptible to form hydrogen bonds with these polar functional groups and then remain in the composites [11]. The hollow structure of plant fibers further facilitates the absorption of water molecules of bio-composites. Several studies demonstrate that bio-composites can achieve a high weight increase of over $10 \%$ within few months immersed into water $[12,13]$. 
A degradation of bio-composites in mechanical properties caused by water absorption is reported as well. Modulus was pointed out to decrease significantly [14]. Fiber-matrix interface weakening and plasticization phenomena were found to be the main damage mechanisms induced by water ageing [15].

Apparently, the abovementioned moisture sensitivity of bio-composites in mechanical properties should be overcome to further extend its applications in structural components. Fiber treatments are promising to address the moisture absorption issue if fiber-matrix bonding is improved [6]. Among the proposed fiber treatments on plant fibers up to now, influence of the mechanical properties of composites was mainly reported [16]. Only few focused on the influence of treatments on the moisture absorption properties of composites and the effects of treatment on preservation of mechanical properties after moisture absorption. Among them, Gassan et al. [17] produced jute fiber epoxy composites and obtained a reduced water uptake of $10-20 \%$ by applying silane treatment on the jute fibers. A reduction of moisture effects on mechanical properties was pointed out. Kushwaha and Kumar [18] investigated the effect of silane treatments on the water absorption properties of bamboo matting reinforced epoxy composites. A decrease in water uptake was obtained, from $41 \%$ to $24 \%$. Similarly, Zahari et al. [19] revealed that silane treated ijuk fiber composites had not much difference in water absorption compared to the untreated counterparts. Zhu et al. [20] performed five commonly used pretreatments on flax fibers; water resistance of composites with treated fibers were not improved as expected, except for a slight improvement by alkaline treatment.

Hence, fiber pre-treatment is a promising way to reduce moisture absorption of natural composites. However, further investigations on fiber treatments are still required to improve moisture resistance of natural fiber composites and to better understand the effects of treatments on the water absorption of composites. Furfuryl alcohol (FA) therefore came into our view, being a promising reactant material for treatments on natural fibers. FA is considered as a green chemical because it is mass produced from green renewable agricultural wastes [21,22]. Apart from the environmental merit, it has several advantages for treatments, such as low viscosity and low molecular weight, which allow in-situ polymerization after penetrating into fiber cells. Applications of furfuryl alcohol can already be found in wood preservation to enhance the moisture resistance and dimensional stability of cellulosic woods [23-25]. For natural fiber reinforced composites, few studies are available on the manufacture full bio-composites with polymerized furfuryl alcohol (PFA) as the matrix, while problems of compatibility and solvent removal remain to be addressed [21,26,27]. As for fiber pretreatment with FA, Saw et al. [28] conducted a study in which luffa cylindrical fiber was grafted with FA followed by oxidation. Thermal and mechanical properties of composites was reported to be improved. However, to our knowledge, very few studies have applied treatment on flax fibers with FA. An alternative green fiber pretreatment on flax fibers with FA is then proposed, aiming to improve the water resistance of flax fiber composites used in structural applications.

This paper aims to investigate a green FA pretreatment on flax fibers and its influence on the mechanical and retention properties of flax fiber composites upon moisture absorption. Two different parameters were chosen to investigate the influence of heating cycles on the effects of treatment. Changes in fiber bundle strength caused by treatments were highlighted. Unidirectional composites reinforced with treated and untreated flax fibers were manufactured by vacuum assistant resin transform molding. Moisture resistance of composites was evaluated by water absorptions tests. Specimens were immersed into distilled water bath for different durations to obtain different moisture contents. Mechanical properties of composites with three different moisture contents were then analyzed to compare the influence of treatment on the retention properties of composites. 


\section{Materials and Methods}

\subsection{Bio-Based Epoxy Matrix and Flax Fibers}

The selected matrix was a two-component green epoxy system (InfuGreen 810/SD 8822, mixing ratio in weight 100:31, from Sicomin, Châteauneuf les Martigues, France). The resin (InfuGreen 810, Sicomin, Châteauneuf les Martigues, France) was derived from colza and has a carbon green content of $38 \%$. The used flax fibers were in the form of non-crimp unidirectional fabric (Bcomp Ltd., Fribourg, Switzerland). Fibers were twisted together into yarns and snitched with textured polyester $(1 / \mathrm{cm})$. The fabric had a weight of $300 \pm 5 \% \mathrm{~g} / \mathrm{m}^{2}$. Furfuryl alcohol is a laboratory chemical obtained from Alfa Aesar (supplier: Thermo Fisher GmbH, Karlsruhe, Germany). Applied catalyst for polymerization of furfuryl alcohol was p-Toluenesulfonic acid (PTSA), a product from Sigma-Aldrich Chemie GmbH, Steinheim, Germany.

\subsection{Furfuryl Alcohol Treatment on Flax Fibers}

Furfuryl alcohol solvent was firstly prepared. PTSA was dissolved in distilled water and then mixed with furfuryl alcohol (0.3 g PTSA and $10 \mathrm{~g}$ water for $100 \mathrm{~g}$ FA). Flax fabrics in desired sizes $(280 \mathrm{~mm} \times 270 \mathrm{~mm})$ were impregnated with FA solvent. Content of FA absorbed by flax fabrics was carefully controlled at $40 \% \pm 1 \%$ by using paper towels to absorb excessive FA solvent. Afterwards the impregnated fabrics were wrapped with aluminum foils and placed into oven. Two different heating cycles were used to investigate the effects of temperature on the treatments (Table 1). Treatment 2 was selected as the treatment parameters to investigate the influence of FA treatment on the mechanical properties at different moisture contents. Specimens that underwent Treatment 1 were not evaluated at every moisture content. Only tensile properties before and after $243 \mathrm{~h}$ immersed in water bath (also only part of moisture absorption tests) were investigated for Treatment 1 to analyze whether a different heating cycle would impose a significant influence on the effects of FA treatment. It should also be noted that the selected high temperatures in this work were determined by Malte Thomsen, who worked under the author's supervision to find satisfactory treatment parameters in preliminary investigations.

Table 1. Heating cycles of furfuryl alcohol (FA) treatments.

\begin{tabular}{cc}
\hline Treatments & Heating Cycles \\
\hline $\mathrm{T} 1$ & $120^{\circ} \mathrm{C}$ for $6 \mathrm{~h} \rightarrow 150^{\circ} \mathrm{C}$ for $4.5 \mathrm{~h}$ \\
$\mathrm{~T} 2$ & $120^{\circ} \mathrm{C}$ for $2 \mathrm{~h} \rightarrow 150^{\circ} \mathrm{C}$ for $7 \mathrm{~h}$ \\
\hline
\end{tabular}

\subsection{Composite Manufacturing}

Composites were manufactured through vacuum assisted resin transfer molding. Vacuum was applied during the resin infusion process to assure a low porosity level. Pressurized air ( 2 bar) was applied after resin infusion during the whole curing cycle $\left(30^{\circ} \mathrm{C}\right.$ for $8 \mathrm{~h}$ followed by $60{ }^{\circ} \mathrm{C}$ for $\left.16 \mathrm{~h}\right)$. The resulting composites have a fiber volume fraction of $40 \%$, calculated by surface density of flax fabrics and density of flax fibers.

\subsection{Water Absorption}

Water absorption was conducted according to ISO-62 [29]. Samples were cut (dry cutting with air as the coolant) into sizes for the tensile tests detailed in the following section. Edges of specimen were carefully polished using a two-step process (grit sizes of sand paper: 320, 1000) to eliminate the influence of edge quality on water uptake. Polished specimens were then conditioned in a desiccator for $12 \mathrm{~h}$ at controlled temperature $\left(20^{\circ} \mathrm{C}\right)$ and relative humidity $(35 \% \mathrm{RH})$. They were then immersed into distilled water bath (room temperature) for $40 \mathrm{~h}, 115 \mathrm{~h}$ and $243 \mathrm{~h}$ to obtain different moisture 
contents. Water absorption behavior was studied by investigating the weight change of the specimens. It was calculated using the following equation:

$$
C_{t}=\frac{m_{2}-m_{1}}{m_{1}} \times 100
$$

where $C_{t}$ is weight change of a specimen after an arbitrary time interval $t$ being immersed; $m_{2}$ is the mass of tested specimen after immersion; and $m_{1}$ is the initial mass of tested specimen after conditioning in desiccator.

\subsection{Mechanical Tests on Composites}

Tensile properties in fibers direction $\left(0^{\circ}\right)$ and perpendicular to fiber direction $\left(90^{\circ}\right)$ were tested according to ASTM 3039 [30]. Load capacity levels of test machines and basic test set-ups are listed in Table 2. Five replicate specimens were tested for each treatment condition, except that four specimens were tested in the case of $0^{\circ}$ specimen immersed for $243 \mathrm{~h}$. For $0^{\circ}$ specimens, Young's modulus was defined via the secant modulus between two strain points: $0.05 \%$ and $0.25 \%$. For $90^{\circ}$ specimens, the same method was used to calculate the transverse modulus, expect that the chosen two strain points are $0.2 \%$ and $0.3 \%$ to avoid the pronounced slack found at the initial loading stage. Strain data of $90^{\circ}$ specimen were obtained from the displacement of traverse. The used sample clamp and testing machine were considered as ideally stiff. However, the transverse modulus calculated in this work is lower than the value predicted by role of mixture. Therefore, the data might not reflect the true intrinsic properties of the composites. Typical problem of grip compliance could be responsible for the deviation. Hence the apparent transverse modulus is then used for phrasing in this paper, instead of transverse modulus. Since the same clamp was used for all tested samples, comparisons of apparent transverse modulus are still considered to be valid.

Table 2. Tensile tests set-ups.

\begin{tabular}{ccccc}
\hline Specimen & Testing Machine & Specimen Dimensions $\mathbf{( m m )}$ & Strain Measurement & Testing Speed \\
\hline $0^{\circ}$ & Zwick $100 \mathrm{kN}$ & $2 \times 18 \times 250$ & Clip-on extensometer & $2 \mathrm{~mm} / \mathrm{min}$ \\
$90^{\circ}$ & Zwick $2.5 \mathrm{kN}$ & $2 \times 20 \times 110$ & Displacement of traverse & $1 \mathrm{~mm} / \mathrm{min}$ \\
\hline
\end{tabular}

\subsection{Tensile Tests on Flax Fiber Bundles (Yarns)}

Individual flax fiber bundles were extracted directly from flax fabrics at random. Paper tapes were wrapped at both ends of yarn for load introduction. The distance between tape ends was $100 \mathrm{~mm}$. All yarns were loaded at a speed of $5 \mathrm{~mm} / \mathrm{min}$ until breakage. It should be noted that the cross section area of yarns was not measured because of the large scatter along with one individual yarn and the irregular shape of the cross section. Only the breaking forces were evaluated. At least 10 yarns were extracted from for each type of fabrics at random and then tested.

\subsection{Scanning Electron Microscope (SEM)}

In this paper, SEM observation was conducted on Phenom XL (Thermo Fisher Scientific, Phenom-World B.V., Eindhoven, The Netherlands). Secondary Electron Detection (SED) was chosen under an acceleration voltage of $10 \mathrm{kV}$ for high quality pictures. All samples were sputtered a thin layer of gold in thickness of about $6.5 \mathrm{~nm}$.

\subsection{Fourier Transform Infrared Spectroscopy (FTIR)}

FTIR analysis was applied to investigate the polymerization degree of FA. Tests were performed on Bruker TENSOR II (Bruker Corporation, Billerica, MA, USA) with an ATR-unit (Attenuated Total Reflection). The chosen range was from $500 \mathrm{~cm}^{-1}$ to $4000 \mathrm{~cm}^{-1}$. The resolution was determined to 
be $4 \mathrm{~cm}^{-1}$ and the spectra were averaged over 16 scans. Spectra from five different locations on each treated or untreated flax fabric were measured, and the average spectra were used.

\section{Results}

\subsection{Characterization of FA Treatment}

Impregnated FA in the flax fabrics polymerized into PFA after the heating treatments. The color of flax fabric turned from off white to yellow-red (Figure 1) after FA treatment. Such change of color is ascribed to the formation of chromophore during polymerization process of FA [22,27]. Weight gain of flax fabrics after FA Treatment 2 is about $10 \%$, while flax fabrics that underwent Treatment 1 have a slightly higher weight gain of about $11 \%$.

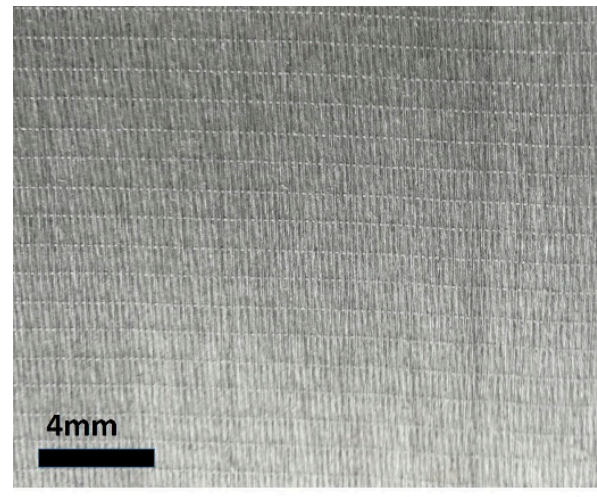

(a)

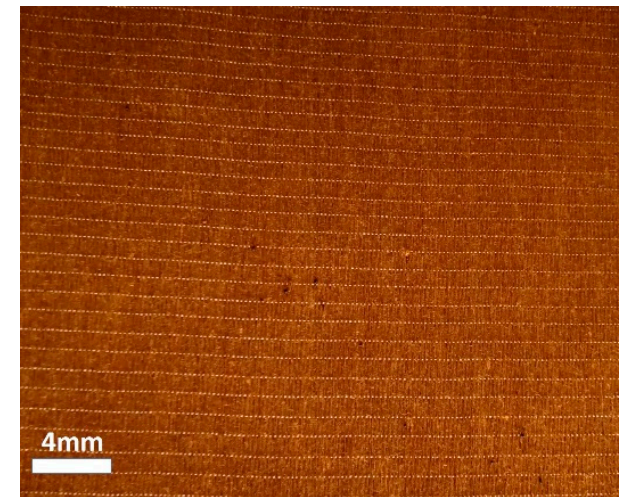

(b)

Figure 1. (a) Untreated flax fiber fabric; and (b) furfuryl alcohol (FA) treated flax fiber fabric.

A closer observation on the influence of FA treatment on fiber surface morphology was achieved by SEM. As shown in Figure 2a, most areas of untreated flax fibers surfaces exhibit a smooth appearance, with only some degraded regions probably caused by over retting during flax fiber production. In contrast, parts of treated flax fiber surfaces were covered by thin layers of winkle materials, which can be recognized as PFA (Figure $2 b$ ).

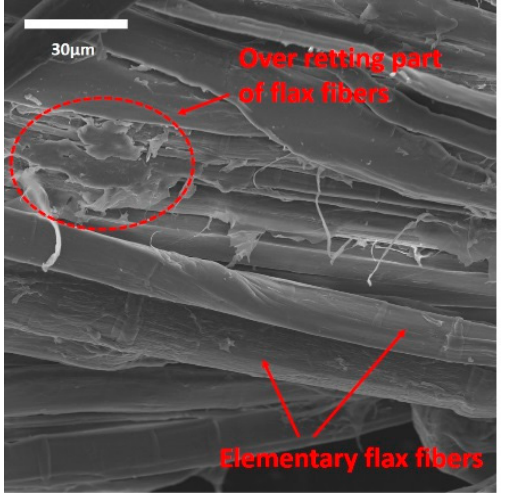

(a)

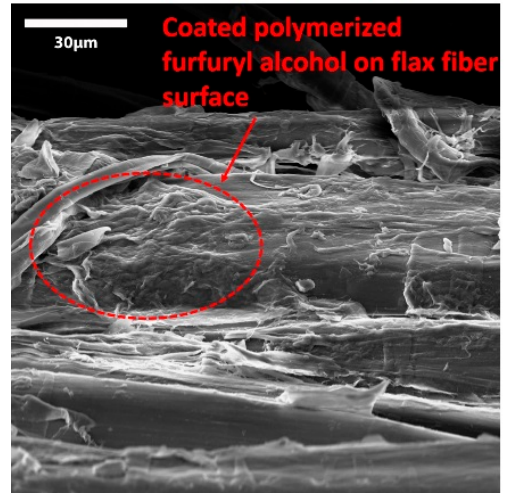

(b)

Figure 2. (a) Morphology of untreated flax fiber surfaces; and (b) morphology of FA treated flax fiber surfaces.

FTIR spectra of treated flax fabric also give indication of presence of PFA on the flax fiber surfaces (Figure 3). The broad band from $3000 \mathrm{~cm}^{-1}$ to $3600 \mathrm{~cm}^{-1}$ shows a fading after the FA treatment, 
owing to the reduced hydroxyl groups on the flax fiber surfaces which are covered by PFA coating. Peaks at $1704 \mathrm{~cm}^{-1}$ and $1504 \mathrm{~cm}^{-1}$, which are the feature peaks of the furan rings [21,26], indicate the presence of PFA. No significant difference was observed between spectra of two treated flax fabrics.

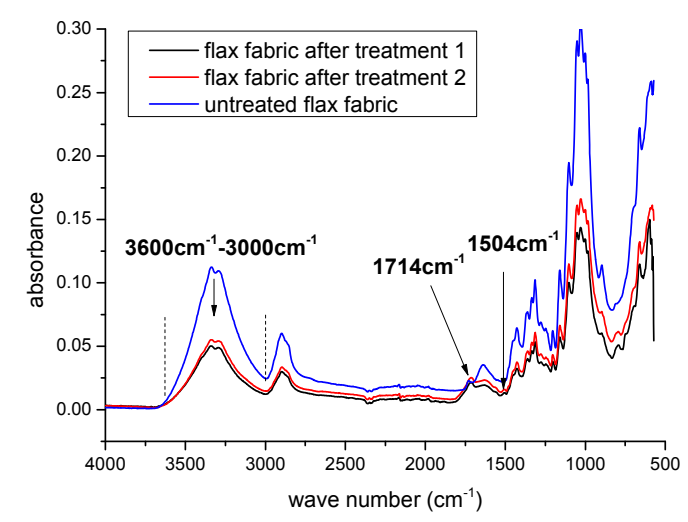

Figure 3. Infrared spectrum of FA treated and untreated flax fabrics.

\subsection{Tensile Tests on Flax Fiber Bundles}

Figure 4 shows representative force-elongation curves from tensile tests of flax fiber bundles. All types of yarns exhibit brittle tensile behavior. FA treated yarns tended to have a considerably stiffer response upon tensile loads. However, a weakening effect was observed for treated yarns. As summarized in Table 3, the strength of yarns was significantly reduced by FA treatments. Treated yarns broke at lower load levels and resist much less deformation before fracture comparing to untreated yarns. No significant difference was observed between two treatments.

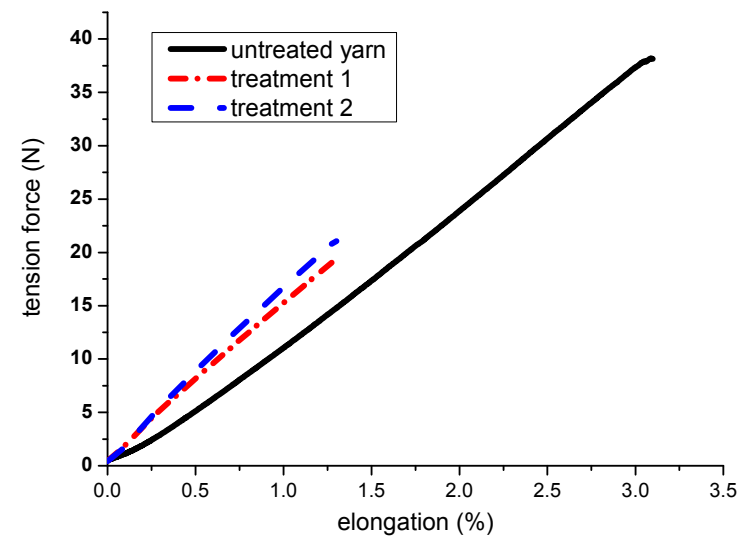

Figure 4. Representative tensile force-elongation curves of treated and untreated yarns.

Table 3. Tensile test results of FA treated and untreated yarns (average and standard deviation).

\begin{tabular}{ccc}
\hline Treatments & Break Force $\mathbf{( N )}$ & Strain at Breakage (\%) \\
\hline untreated & $37.16 \pm 2.94$ & $2.94 \pm 0.43$ \\
T1 & $19.76 \pm 6.75$ & $1.108 \pm 0.356$ \\
T2 & $20.17 \pm 5.49$ & $1.171 \pm 0.36$ \\
\hline
\end{tabular}

\subsection{Moisture Absorption Tests}

Results from moisture absorption tests are summarized in Table 4. It can be seen that composites reinforced with FA treated fibers show superior properties of moisture absorption reduction comparing 
to their untreated counterparts. Moreover, an improvement in moisture resistance was observed over the whole investigated time span $(40 \mathrm{~h}, 115 \mathrm{~h}$ and $243 \mathrm{~h})$, as displayed in Table 4 . Water absorption measured by weight increase was higher for $90^{\circ}$ specimens for both treated and untreated composites.

Table 4. Weight increase (\%) of FA treated and untreated composites after water absorption (average and standard deviation).

\begin{tabular}{ccccccc}
\hline \multirow{2}{*}{ Time (h) } & \multicolumn{3}{c}{$\mathbf{0}^{\circ}$ Samples } & \multicolumn{3}{c}{$\mathbf{9 0}^{\circ}$ Samples } \\
\cline { 2 - 7 } & Untreated & T1 & T2 & Untreated & T1 & T2 \\
\hline 40 & $0.630 \pm 0.042$ & $0.405 \pm 0.170$ & $0.415 \pm 0.144$ & $1.294 \pm 0.209$ & $0.569 \pm 0.093$ & $0.593 \pm 0.082$ \\
115 & $1.358 \pm 0.144$ & - & $0.829 \pm 0.166$ & $3.199 \pm 0.321$ & - & $1.311 \pm 0.135$ \\
243 & $2.414 \pm 0.170$ & $1.389 \pm 0.119$ & $1.380 \pm 0.093$ & $5.204 \pm 0.337$ & - & $2.755 \pm 0.442$ \\
\hline
\end{tabular}

\subsection{Tensile Tests on Flax Fiber Composites}

Tensile tests results are summarized in Tables 5 and 6. Different responses after FA treatments were observed in $0^{\circ}$ and $90^{\circ}$ specimen. The tensile strength in fiber direction (longitudinal tensile strength) was observed to decrease after FA treatment, while the longitudinal Young's modulus increased. On the contrary, both the tensile strength and modulus perpendicular to fiber direction (transverse) demonstrate higher values for FA treated ones.

Table 5. Tensile properties in fiber direction of FA treated and untreated composites after water absorption (average and standard deviation).

\begin{tabular}{ccccccc}
\hline \multirow{2}{*}{ Time (h) } & \multicolumn{2}{c}{ Untreated } & T2 & T1 \\
\cline { 2 - 7 } & Strength (MPa) & Young Modulus (GPa) & Strength (MPa) & Young Modulus (GPa) & Strength (MPa) & Young Modulus (GPa) \\
\hline 0 & $290.00 \pm 3.08$ & $20.17 \pm 0.52$ & $196.40 \pm 4.62$ & $23.62 \pm 0.38$ & $200.6 \pm 17.37$ & $23.8 \pm 1.33$ \\
40 & $271.20 \pm 12.60$ & $17.32 \pm 0.46$ & $194.2 \pm 4.02$ & $21.34 \pm 0.15$ & - & - \\
115 & $255.00 \pm 12.59$ & $15.50 \pm 0.25$ & $186.00 \pm 6.89$ & $20.42 \pm 0.25$ & - & - \\
243 & $265.3 \pm 15.13$ & $13.46 \pm 0.47$ & $180.00 \pm 5.58$ & $20.77 \pm 0.06$ & $180.5 \pm 2.38$ & $20.4 \pm 0.25$ \\
\hline
\end{tabular}

Table 6. Tensile properties perpendicular to fiber direction of FA treated and untreated composites after water absorption (average and standard deviation).

\begin{tabular}{ccccccc}
\hline \multirow{2}{*}{ Time (h) } & \multicolumn{2}{c}{ Untreated } & T2 & T1 \\
\cline { 2 - 7 } & Strength (MPa) & Apparent Modulus (GPa) & Strength (MPa) & Apparent Modulus (GPa) & Strength (MPa) & Apparent Modulus (GPa) \\
\hline 0 & $25.87 \pm 0.92$ & $0.494 \pm 0.029$ & $28.36 \pm 2.04$ & $0.547 \pm 0.026$ & $27.74 \pm 1.71$ & - \\
40 & $21.24 \pm 0.96$ & $0.425 \pm 0.017$ & $24.67 \pm 0.97$ & $0.529 \pm 0.022$ & - & - \\
115 & $18.20 \pm 1.03$ & $0.424 \pm 0.020$ & $22.54 \pm 0.58$ & $0.526 \pm 0.016$ & - & - \\
243 & $18.34 \pm 0.81$ & $0.383 \pm 0.018$ & $20.41 \pm 0.75$ & $0.443 \pm 0.011$ & $20.15 \pm 0.99$ & $0.462 \pm 0.009$ \\
\hline
\end{tabular}

Upon water absorption, all tested composites show decreasing trends in both tensile strengths and modulus (longitudinal and transverse). Comparing to untreated composites, tensile properties of treated composites are better retained after moisture absorption.

\section{Discussion}

\subsection{Influence of FA Treatment on the Mechanical Properties of Composites}

Obviously, the FA treatment imposes a significant effect on the tensile properties of composites. As can be seen in Figure 5, tensile strength in fiber direction is significantly degraded (by about 30\%) after FA treatments. Such degradation was also observed in the fiber bundle tensile tests on treated yarns. Break forces of FA treated yarns was found to be reduced by over $45 \%$ (Table 3 ). The consistence between two tests can thus explain the sink of tensile properties in fiber direction. In fact, it has been reported that cellulosic natural fibers can be degraded under acid conditions at high temperatures [31]. Marshall [32] also mentioned a significant strength reduction of flax/cotton nonwoven mat after heating $\left(60{ }^{\circ} \mathrm{C}\right.$ and $\left.120^{\circ} \mathrm{C}\right)$ with citric acid. When applying tensile loading in fiber direction, the 
fibers carry the main load and any weakening of their mechanical properties by degradation would correspondingly result in a decreased maximum load the composites can carry. The treatments in this paper applied a high temperature of $150{ }^{\circ} \mathrm{C}$ under strong acid condition, thus can be an important attributing factor to the decrease of tensile properties in fiber direction.

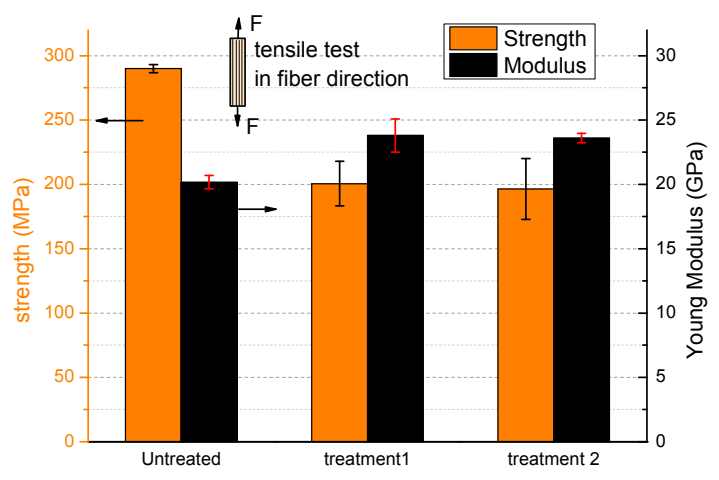

Figure 5. Influence of FA treatments on the tensile properties of composites in fiber direction (error bars indicate standard deviation).

Further investigation on the tensile tests of $90^{\circ}$ composites allowed evaluating the effects of treatment on fiber-matrix interfacial bonding properties. As displayed in Table 6, the slight increase in transverse tensile strength and modulus of treated composites could be an indication of improved fiber-matrix bonding properties. In fiber reinforced laminates, good fiber-matrix bonding properties impede the propagation of critical flaw and cracks, resulting in high transverse tensile strengths [33].

The improved fiber-matrix bonding could result from two-fold mechanisms. Firstly, the treated yarns are more compatible with the hydrophobic matrix, owing to the fact that coated PFA on the fiber surfaces increases the hydrophobicity. Secondly, as already shown in Figure 2b, treated fiber surfaces are rougher and offer a larger surface area to interact with matrix. SEM observations on the fracture surface of $90^{\circ}$ composites also prove a good fiber-matrix bonding for treated composites. The PFA at interfaces both on and inside a fiber bundle were found to join flax fibers and the matrix strongly, showing no clearance between each other (Figure 6b). Although no conclusive evidence could be given whether there are chemical bonds generated between PFA and matrix, the strong bonding between flax fibers and PFA could be resulted from the formation of covalent bonds through the reactions between PFA chains and hydroxyl groups of lignin on flax fiber surfaces [25,28]. In comparison, debonding between flax fiber bundles and matrix was observed at the interfaces for untreated composites, indicating an inferior bonding between flax fibers and matrix (Figure 6a).

Degradation in strength is a disadvantage of the applied treatment, whereas the Young's modulus of composites in fiber direction is improved by about $18 \%$. This can be partly attributed to a better fiber-matrix bonding as discussed above. A strong fiber-matrix bonding facilitates load transfer from matrix to fibers without causing much deformation in the interfacial regions. On the other hand, coated PFA might have a stiffening effect on loaded fibers (Figure 4). It is assumed that FA penetrates inside the yarns or even possibly in the fiber cells and polymerize into stiff PFA, replacing weak parts of fibers or connections between individual fibers. This would also explain the experimental results for the fiber yarns, but further investigations are necessary to verify this hypothesis. 


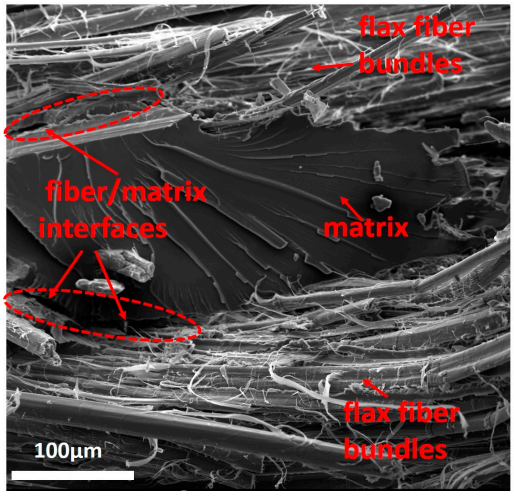

(a)

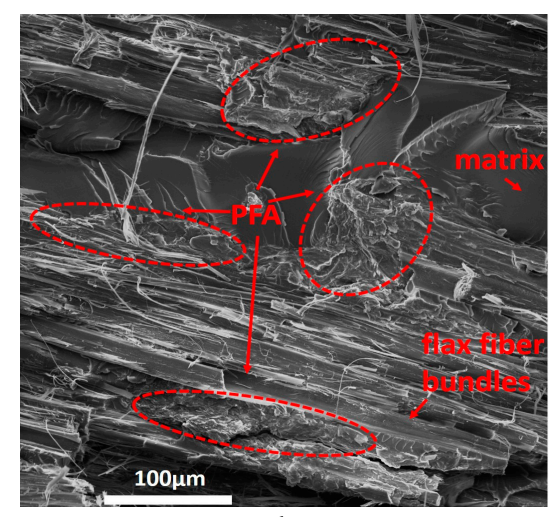

(b)

Figure 6. (a) Morphology of fracture surface of untreated flax fiber composites; and (b) morphology of fracture surface of FA treated flax fiber composites.

\subsection{Influence of FA Treatment on the Moisture Absorption of Composites}

Applying FA treatment on flax fibers leads to the expected improvement in moisture absorption retardation. For $0^{\circ}$ specimens that underwent FA Treatment 2, the amount of water uptake after $40 \mathrm{~h}$, $115 \mathrm{~h}$ and $243 \mathrm{~h}$ was reduced by $34 \%, 39 \%$ and $42.4 \%$, respectively, compared with untreated composites (Figure 7). Absorbed water amount of composites after over 10 days reached only $1.389 \%$ of original weight, while the untreated composites absorb nearly twice as much water. The improvement of moisture resistance can be ascribed to the better fiber-matrix bonding of the composites which impede the propagation of water molecules along with the fiber-matrix interfaces. Furthermore, flax fibers were more hydrophobic after FA treatment owing to the introduction of PFA on the flax fibers or inside flax fiber cells. In fact, PFA is stated to have an excellent water resistance property. Water uptake of PFA at saturation was reported to have a value of $1.12 \%$ [21], which is lower than commonly used polymer matrixes, including the selected bio-epoxy in this work.

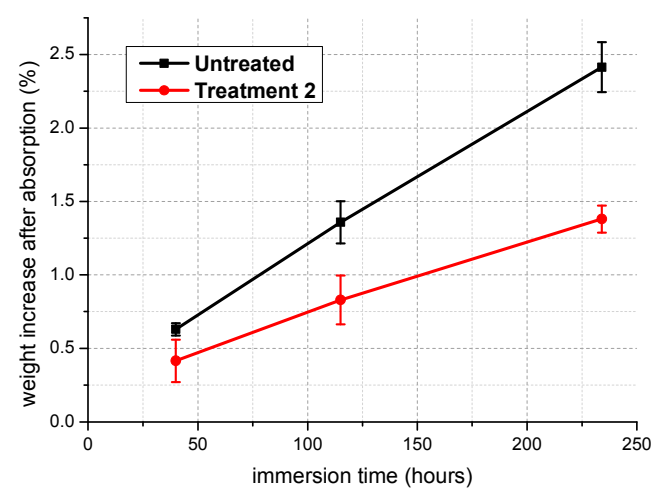

Figure 7. Influence of FA treatments on the water uptake of $0^{\circ}$ specimen (error bars indicate standard deviation).

\subsection{Influence of FA Treatment on the Retention Properties of Composites after Water Absorption}

Retention of mechanical properties in wet conditions is vitally important for composites used in structural applications. Severe degradation of wet composites in mechanical properties is the major reason moisture resistance of composites is required to be improved.

Figure 8 displays the retention of tensile properties of FA treated specimen (T2) and untreated specimen. The tensile properties of treated composites are better maintained compared to the untreated ones at the same immersion duration. Longitudinal tensile strength of treated composites only 
decreased by $5.3 \%$ after $>5$ days immersed in water, while their untreated counterparts showed a decrease of $15.5 \%$ over the same time span. When it comes to transverse strength, both types of composites show a pronounced decrease along with the immersion time. Untreated composites again demonstrated a worse retention compared to FA treated ones, especially over the first $115 \mathrm{~h}$ in water, indicating a faster degradation in fiber-matrix bonding. This is further testified by SEM observations on $90^{\circ}$ specimen fracture surfaces. As depicted in Figure 9, there is an evident difference in the fractographic features for untreated composites before and after water absorption, while no obvious change was observed for FA treated composites. Figure 9a depicts the loose fiber bundles/matrix bonding of untreated composites, with flax fibers still bunching up together in the original from of yarns. After absorbing moisture over five days, inter-fiber splitting inside fiber bundles was noticed (Figure 9b), indicating that inter-fiber bonding was weakened significantly by the absorbed water molecules. In contrast, FA treated composites show similar fractographic features of tight flax fiber-matrix bonding and broken fibers bunches before and after $115 \mathrm{~h}$ in water, revealing a better resistance of fiber-matrix bonding against water uptake.

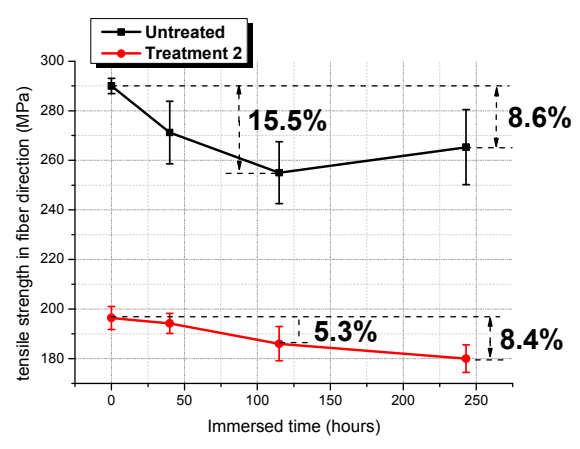

(a)

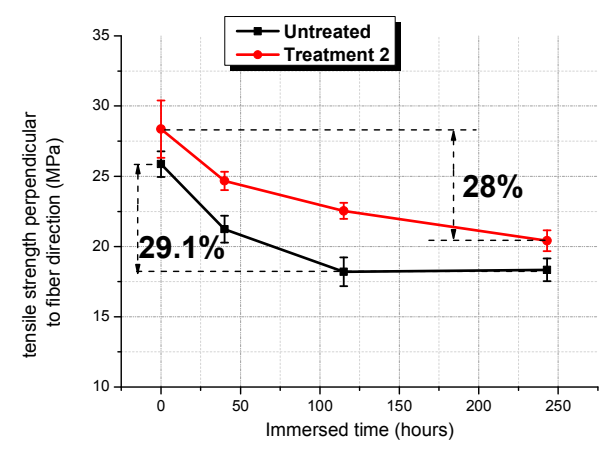

(b)

Figure 8. Comparison of retention rates in tensile strength after water uptake: (a) comparison of longitudinal tensile strength between treated and untreated composites; and (b) comparison of transverse tensile strength between treated and untreated composites. (Error bars indicate standard deviation).

Figure 10a shows the retention of Young's modulus in fiber direction, which is an indication of load transfer efficiency at fiber-matrix interfaces and intrinsic fiber tensile modulus. It is clearly revealed that FA treatment on composites demonstrated not only a significantly increased stiffness over the untreated composites (Table 5), but also reserve larger extent of Young's modulus. Stronger fiber-matrix bonding again explains the better resistance on degradation at fiber-matrix interfaces. Meanwhile, the higher hydrophobicity of flax fibers also impeded the plasticizing effect on flax fibers caused by water absorption, which could be responsible for the widening superiority of treatment at longer submersion in water (after $243 \mathrm{~h}$ ). Similar effects of FA treatment were also observed for transverse modulus (Figure 10b and Table 6), except that the advantage at longer exposure to water was weakened. In fact, the transverse modulus was dominated by the matrix modulus and also fiber-matrix interface stiffness. During the first $115 \mathrm{~h}$ in water, degradation in fiber-matrix stiffness of treated composites was less severe for the untreated ones; the treated ones thus maintain a high fiber-matrix stiffness. The matrix stiffness degradation by water absorption could be to some extent compensated. However, it is likely that the compensation effect was weakened upon longer exposure, owing to the fact that both fiber-matrix stiffness and matrix stiffness are further reduced. 


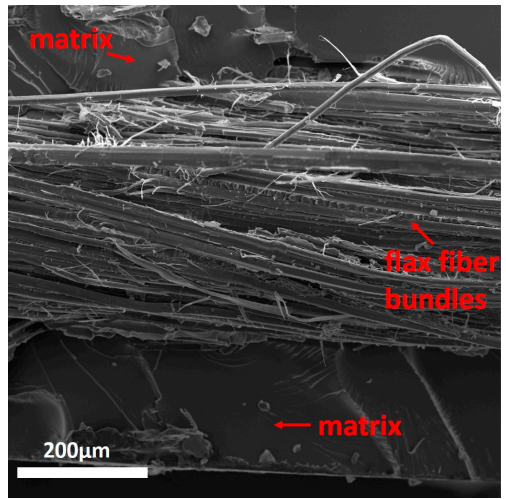

(a)

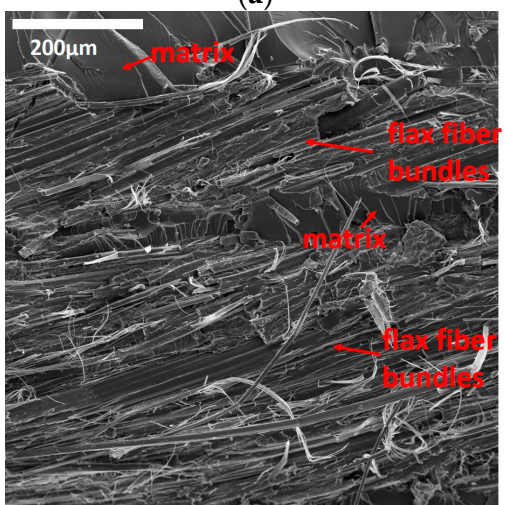

(c)

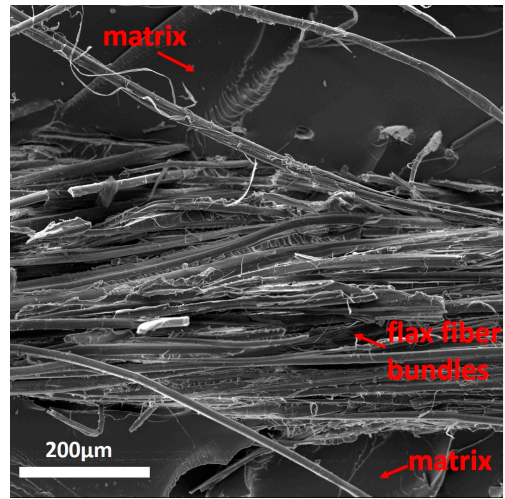

(b)

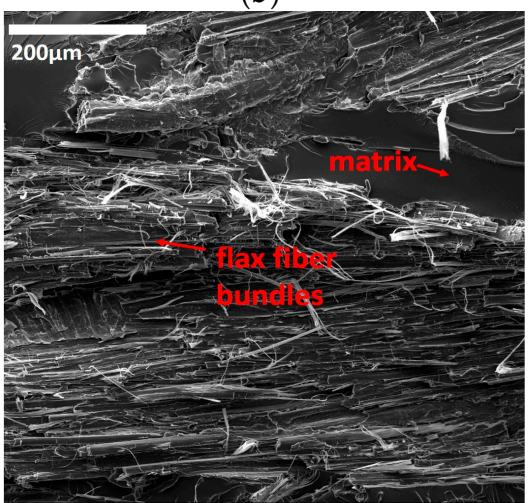

(d)

Figure 9. Morphology of fracture surfaces of $90^{\circ}$ specimens: (a) control group (with untreated flax fibers), $0 \mathrm{~h}$ in water; (b) control group (with untreated flax fibers), $115 \mathrm{~h}$ in water; (c) with flax fibers under Treatment 2 (T2), $0 \mathrm{~h}$ in water; and (d) with flax fibers under Treatment 2 (T2), $115 \mathrm{~h}$ in water.

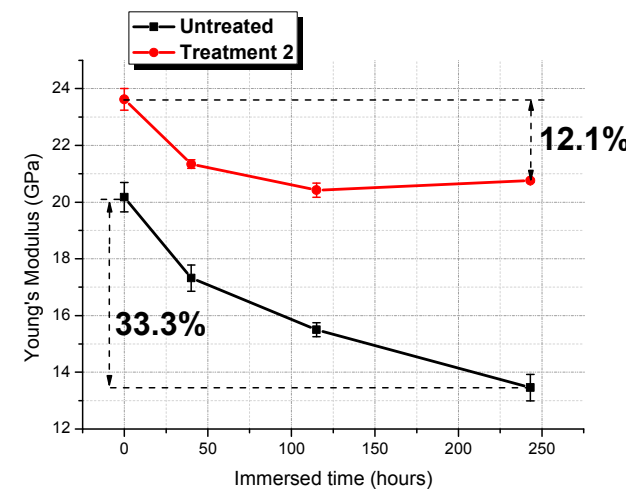

(a)

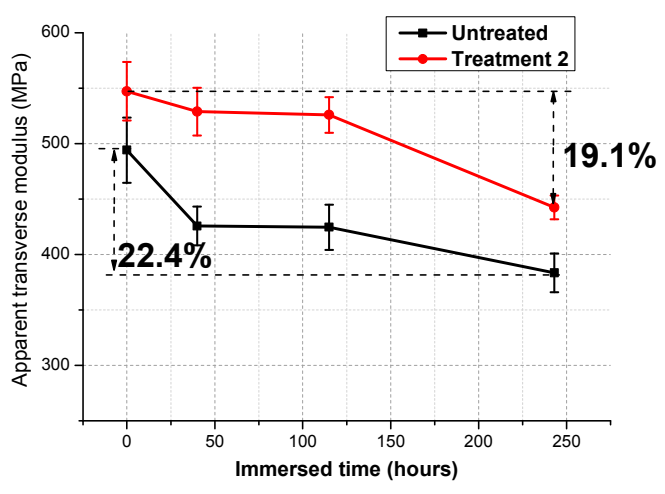

(b)

Figure 10. Change of modulus in fiber direction after water absorption: (a) retention of Young's modulus in fiber direction; and (b) retention of transverse modulus. (Error bars indicate standard deviation).

Interestingly, longitudinal tensile strength of untreated composites after $243 \mathrm{~h}$ in water was higher than after $115 \mathrm{~h}$ in water (Figure 8), showing a "strengthening" effect upon further water absorption, while the transverse tensile strength remained circa 30\% lower. In fact, a high longitudinal tensile strength of unidirectional composites does not necessarily indicate high fiber-matrix bonding [34]. Local stress concentration at broken fiber ends and debonding areas also contribute greatly to the ultimate tensile strength. Under the same fiber-matrix bonding properties, local concentrations in 
untreated composites ( $243 \mathrm{~h}$ in water) was believed to play a less important role because of further plasticizing effects, proven by a higher failure strain of $2.38 \%$ compared to $2.08 \%$ after $115 \mathrm{~h}$ in water. The higher failure strain also means more movement of fibers to a better alignment in the load direction, partly overcoming the fiber misalignment and thus compensate the weakening fiber-matrix bonding.

\subsection{Comparison of FA Treatments with Different Heating Cycles}

The polymerization process of FA into PFA is assumed to involve a series of complex reactions [22,27]. It is sensitive to several parameters such as type of catalysts, catalyst contents, temperature histories by polymerization, FA solvent contents of treated fibers, etc. These parameters could affect the influence of FA treatment on flax fiber composites. This paper gives preliminary attention to the influence of two heating cycles on the effects of FA treatment. As shown in Figure 3 , the FTIR spectrum of both treated flax fibers show no great difference from each other, which indicates basically similar polymerization degrees. The tensile tests on treated fiber bundles also indicates no clear trend of superiority between the two treatments (Table 3). With regard to the effects on the mechanical properties of composites (Tables 5 and 6) and moisture absorption resistance (Table 4), the discrepancy is also perceived to be not significant. It appears that FA treatment is not sensitive to heating cycles within the selected time and temperature span. However, it should be mentioned that both heating cycles were determined to assure a satisfying polymerization degree of FA. Therefore, it is assumed that FA treatment might not be sensitive to temperature histories, as long as the polymerization degree of FA reaches a certain range when other parameters are held constant. However, further research on the influence of the treatment parameters is still required.

\section{Conclusions}

This study investigated a fiber pretreatment on flax fiber composites using furfuryl alcohol. Moisture uptake of resulting composites and their retention in tensile properties were analyzed. The results show an expected improvement in moisture resistance and a better retention of tensile strength and stiffness for treated composites. FA treatment yielded an up to $18 \%$ improved modulus, and the moisture uptake was reduced significantly. The fiber-matrix interfacial bonding was also found to be improved. During the FA treatment in parallel, the acid catalyst reduced the strength of the flax fibers. It was shown that the FA pretreatment is an efficient way to reduce the moisture absorption. Further work has to focus on the catalyst (acid) and treatment process to prevent degradation of the fibers.

Author Contributions: Y.J. and B.F. proposed the idea of FA treatment and conceived the experiments. Y.J. carried out the experiments, data analyzing and wrote the paper. B.F. reviewed and revised the paper.

Funding: This research received no external funding. The publication was supported by the Deutsche Forschungsgemeinschaft (DFG, German Research Foundation)—project number 392323616 and the Hamburg University of Technology (TUHH) in the funding program "Open Access Publishing".

Acknowledgments: Y.J. would like to express his gratitude to China Scholarship Council (CSC) for providing a PhD scholarship. The authors thank Hakan Özdemir for his contribution in part of the experimental work and Malte Thomsen for his preliminary investigation on the FA treatment process.

Conflicts of Interest: The authors declare no conflict of interest.

\section{References}

1. Bodros, E.; Pillin, I.; Montrelay, N.; Baley, C. Could biopolymers reinforced by randomly scattered flax fibre be used in structural applications? Compos. Sci. Technol. 2007, 67, 462-470. [CrossRef]

2. Faruk, O.; Bledzki, A.K.; Fink, H.-P.; Sain, M. Progress Report on Natural Fiber Reinforced Composites. Macromol. Mater. Eng. 2014, 299, 9-26. [CrossRef]

3. Shah, D.U.; Schubel, P.J.; Clifford, M.J. Can flax replace E-glass in structural composites? A small wind turbine blade case study. Compos. Part B Eng. 2013, 52, 172-181. [CrossRef] 
4. Goutianos, S.; Peijs, T.; Nystrom, B.; Skrifvars, M. Development of Flax Fibre based Textile Reinforcements for Composite Applications. Appl. Compos. Mater. 2006, 13, 199-215. [CrossRef]

5. Ku, H.; Wang, H.; Pattarachaiyakoop, N.; Trada, M. A review on the tensile properties of natural fiber reinforced polymer composites. Compos. Part B Eng. 2011, 42, 856-873. [CrossRef]

6. Pickering, K.L.; Efendy, M.A.; Le, T.M. A review of recent developments in natural fibre composites and their mechanical performance. Compos. Part A Appl. Sci. Manuf. 2016, 83, 98-112. [CrossRef]

7. Jauhari, N.; Mishra, R.; Thakur, H. Natural Fibre Reinforced Composite Laminates-A Review. Mater. Today 2015, 2, 2868-2877. [CrossRef]

8. Akampumuza, O.; Wambua, P.M.; Ahmed, A.; Li, W.; Qin, X.-H. Review of the applications of biocomposites in the automotive industry. Polym. Compos. 2017, 38, 2553-2569. [CrossRef]

9. Zini, E.; Scandola, M. Green composites: an overview. Polym. Compos. 2011, 32, 1905-1915. [CrossRef]

10. Shekar, H.S.; Ramachandra, M. Green Composites: A Review. Mater. Today 2018, 5, 2518-2526. [CrossRef]

11. Mokhothu, T.H.; John, M.J. Review on hygroscopic aging of cellulose fibres and their biocomposites. Carbohydr. Polym. 2015, 131, 337-354. [CrossRef] [PubMed]

12. Hristozov, D.; Wroblewski, L.; Sadeghian, P. Long-term tensile properties of natural fibre-reinforced polymer composites: Comparison of flax and glass fibres. Compos. Part B Eng. 2016, 95, 82-95. [CrossRef]

13. Cheour, K.; Assarar, M.; Scida, D.; Ayad, R.; Gong, X.-L. Effect of water ageing on the mechanical and damping properties of flax-fibre reinforced composite materials. Compos. Struct. 2016, 152, 259-266. [CrossRef]

14. Assarar, M.; Scida, D.; El Mahi, A.; Poilâne, C.; Ayad, R. Influence of water ageing on mechanical properties and damage events of two reinforced composite materials: Flax-fibres and glass-fibres. Mater. Des. 2011, 32, 788-795. [CrossRef]

15. Chilali, A.; Zouari, W.; Assarar, M.; Kebir, H.; Ayad, R. Effect of water ageing on the load-unload cyclic behaviour of flax fibre-reinforced thermoplastic and thermosetting composites. Compos. Struct. 2018, 183, 309-319. [CrossRef]

16. Kabir, M.M.; Wang, H.; Lau, K.T.; Cardona, F. Chemical treatments on plant-based natural fibre reinforced polymer composites: An overview. Compos. Part B Eng. 2012, 43, 2883-2892. [CrossRef]

17. Gassan, J.; Bledzki, A.K. Effect of moisture content on the properties of silanized jute-epoxy composites. Polym. Compos. 1997, 18, 179-184. [CrossRef]

18. Kushwaha, P.K.; Kumar, R. Studies on water absorption of bamboo-epoxy composites: Effect of silane treatment of mercerized bamboo. J. Appl. Polym. Sci. 2010, 115, 1846-1852. [CrossRef]

19. Zahari, W.; Badri, R.; Ardyananta, H.; Kurniawan, D.; Nor, F.M. Mechanical Properties and Water Absorption Behavior of Polypropylene/Ijuk Fiber Composite by Using Silane Treatment. Procedia Manuf. 2015, 2, 573-578. [CrossRef]

20. Zhu, J.; Zhu, H.; Abhyankar, H.; Njuguna, J. Effect of Fibre Treatments on Water Absorption and Tensile Properties of Flax/Tannin Composites. In Proceedings of the 19th International Conference on Composite Materials, Montreal, QC, Canada, 28 July-2 August 2013.

21. Deka, H.; Misra, M.; Mohanty, A. Renewable resource based "all green composites" from kenaf biofiber and poly(furfuryl alcohol) bioresin. Ind. Crops Prod. 2013, 41, 94-101. [CrossRef]

22. Choura, M.; Belgacem, N.M.; Gandini, A. Acid-catalyzed polycondensation of furfuryl alcohol: Mechanisms of chromophore formation and cross-linking. Macromolecules 1996, 29, 3839-3850. [CrossRef]

23. Li, W.; Wang, H.; Ren, D.; Yu, Y.; Yu, Y. Wood modification with furfuryl alcohol catalysed by a new composite acidic catalyst. Wood Sci. Technol. 2015, 49, 845-856. [CrossRef]

24. Lande, S.; Westin, M.; Schneider, M. Properties of furfurylated wood. Scand. J. For. Res. 2004, 19, 22-30. [CrossRef]

25. Nordstierna, L.; Lande, S.; Westin, M.; Karlsson, O.; Furó, I. Towards novel wood-based materials: Chemical bonds between lignin-like model molecules and poly(furfuryl alcohol) studied by NMR. Holzforschung 2008, 62, 267. [CrossRef]

26. Motaung, T.E.; Gqokoma, Z.; Linganiso, L.Z.; Hato, M.J. The effect of acid content on the poly(furfuryl) alcohol/cellulose composites. Polym. Compos. 2016, 37, 2434-2441. [CrossRef]

27. Crossley, R.J.; Schubel, P.J.; Stevenson, A.; Moreira, M. The Development and Processing of a Sustainable Fully bio Derived Polyfurfuryl Alcohol Matrix Flax Fibre Prepreg. In Proceedings of the 15th European Conference on Composite Materials, Venice, Italy, 24-28 June 2012. 
28. Saw, S.K.; Purwar, R.; Nandy, S.; Ghose, J.; Sarkhel, G. Fabrication, Characterization, and Evaluation of Luffa cylindrica Fiber Reinforced Epoxy Composites. BioResources 2013, 8. [CrossRef]

29. BS EN ISO. 62. Plastics-Determination of Water Absorption 1999; American National Standards Institute: New York, NY, USA, 2007.

30. ASTM. D3039/D3039M. Standard Test Method for Tensile Properties of Polymer Matrix Composite Materials; American Society for Testing and Materials: West Conshohocken, PA, USA, 2000.

31. Wyman, C.E. Ethanol from lignocellulosic biomass: technology, economics, and opportunities. Bioresour. Technol. 1994, 50, 3-15. [CrossRef]

32. Marshall, W.E.; Akin, D.E.; Wartelle, L.H.; Annis, P.A. Citric acid treatment of flax, cotton and blended nonwoven mats for copper ion absorption. Ind. Crops Prod. 2007, 26, 8-13. [CrossRef]

33. Liebig, W.V.; Leopold, C.; Hobbiebrunken, T.; Fiedler, B. New test approach to determine the transverse tensile strength of CFRP with regard to the size effect. Compos. Commun. 2016, 1, 54-59. [CrossRef]

34. Subramanian, S.; Lesko, J.J.; Reifsnider, K.L.; Stinchcomb, W.W. Characterization of the fiber-matrix interphase and its influence on mechanical properties of unidirectional composites. J. Compos. Mater. 1996, 30, 309-332. [CrossRef]

(C) 2018 by the authors. Licensee MDPI, Basel, Switzerland. This article is an open access article distributed under the terms and conditions of the Creative Commons Attribution (CC BY) license (http:/ / creativecommons.org/licenses/by/4.0/). 